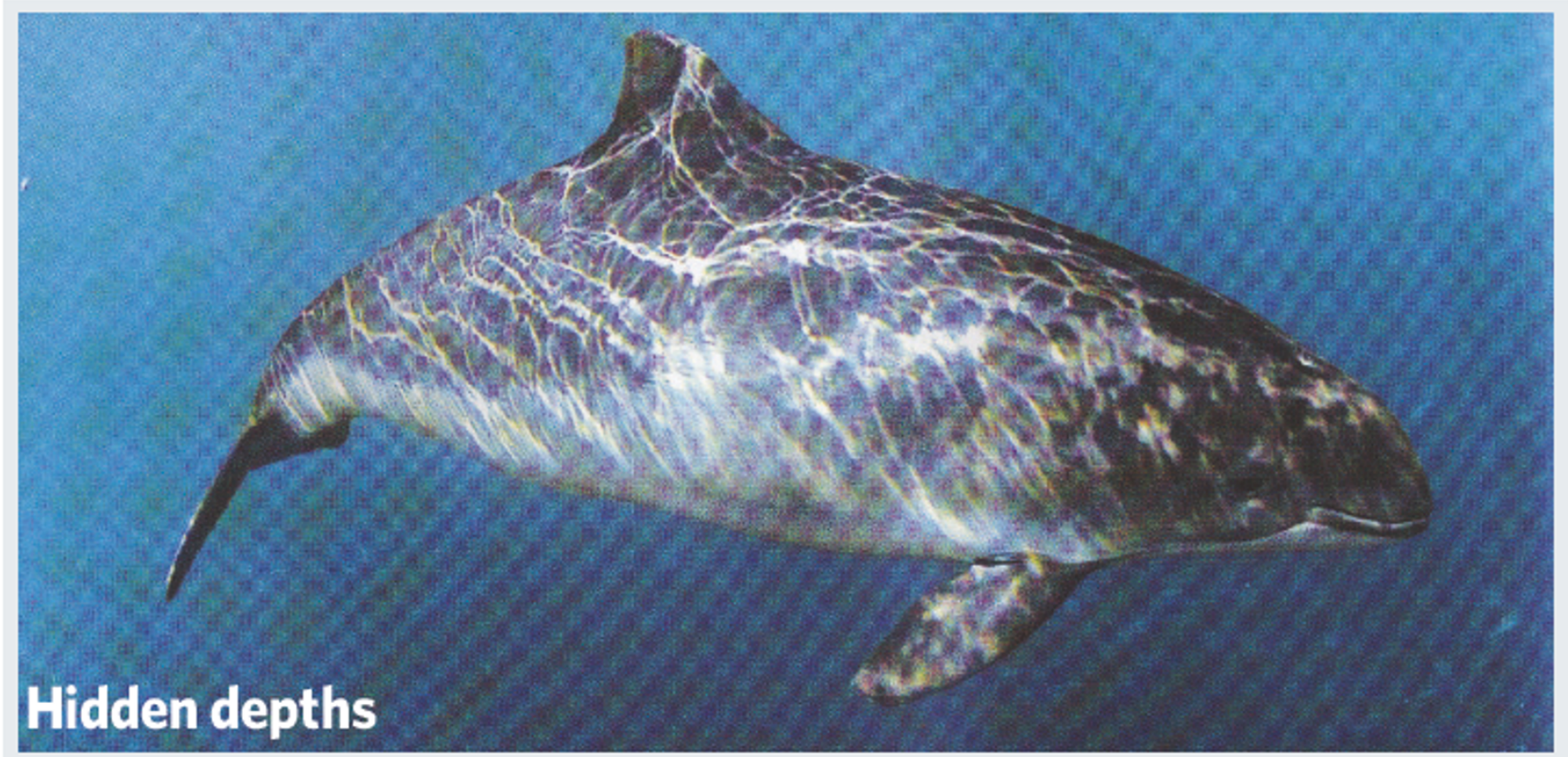

The photographer Bill Curtsinger has completed 33 photographic essays for National Geographic magazine as part of his quest to reveal marine species in their natural settings. The photograph of the harbour porpoise above is from his book Extreme Nature:Images From the World's Edge (White Star, $€ 29.20$ ).

climbed out of, complete with tyre tracks.

Roving Mars is a model of how to draw the public into space exploration. The giant size and excellent sound make the movie especially commanding, but even the TV-resolution DVD that may soon be available would be suitable for showing in schools. A 20-page 'educator guide' can be downloaded from the official website, which includes an excellent 90 -second trailer that samples various parts of the movie.

The film can now be seen at IMAX cinemas across the United States and will be released in other countries later in 2006.

Jay M. Pasachoff is Field memorial professor of astronomy at Williams College, Williamstown, Massachusetts O1267, USA.

\title{
The chamber of wonders
}

\section{From Private to Public: Natural Collections and Muse ums \\ edited by Marco Beretta \\ Science History Publications: 2005. 272 pp. $\$ 39.95$}

\section{Kathie Way}

We have all visited museums of natural history and perhaps been excited, intrigued, inspired — or even thoroughly bored — by the objects on display. But I suspect that we seldom pause to wonder how the contents of these galleries arrived in their mahogany drawer or tabletop vitrine. These essays, edited by Marco Beretta, address and offer answers to this question.

In his excellent preface, Beretta discusses the idea that the emergence of natural history as an independent discipline "was closely connected to the possession and domination of nature, rather than its contemplation". Thus it was the passion for collecting natural-history artefacts from the Renaissance to the end of the eighteenth century that drove the establishment of the discipline. The growth of exploration, the trade routes forged by the East
India Company, and the burgeoning enthusiasm for 'cabinets of curiosity', beginning in the seventeenth century, support this chronology. The 12 expert contributors to this volume provide a wealth of historiographic data drawn from late Antiquity to the nineteenth century, and examine the role of the natural-history collection through time.

Giovanni di Pasquale looks at how the Greeks and Romans documented the past through the accumulation of relics, from the ancient library at Alexandria to the established Roman museums and their collections. The suggestion that collecting relics condemns a still evident culture to the distant past is an interesting one. Susana Gómez López deals with Spanish museum collections from the fifteenth century onwards and concentrates on the link between the scientific thinking of the time and the collections in Seville, a port of entry for commodities, including slaves, from the New World. She uses a number of sixteenth-century personalities, including Spain's King Philip II, to illustrate the collecting ethos of the time and the value of collections in communication. The contemporary importance of access, a vital performance indicator for modern museums, is highlighted.

The Renaissance Wunderkammer, or chamber of wonders, tended to be the private preserve of a rich or royal coterie with the means to indulge their passion for bringing together natural and artistic objects, which were often presented together in ornate cabinets. Alessandro Tosi compares the relatively unscientific Wunderkammer of the German tradition with the great Italian Renaissance collections of Ulisse Aldrovandi, Francesco Calzolari and others, which were almost exclusively devoted to natural history and were an important component of an emerging scientific culture.

Anna Maerker discusses the anatomical collections of La Specola in Florence and the Josephinum in Vienna, and examines the transition of the former from a cabinet of curiosities to a public museum. She also explores how the rejection by both physicians and surgeons of collections of anatomical models, which they dismissed as merely a source of entertainment for the middle dasses, led to a rapprochement of these hitherto rather antagonistic disciplines. Samuel Alberti's article focuses on the concept of ownership of collections, and cites John and William Hunter as private collectors whose anatomical collections became public when they were sold to the University of Glasgow in Scotland; medical students were afforded free access while the public had to pay. Collections made and owned by learned societies formed the basis of today's great regional museums, such as those in Manchester and Sheffield, and Alberti compares the ways in which such regional museums developed.

The paper by Jonathan Simon on eighteenth- 
century mineral collections considers private collections in Paris and focuses on issues of taste and aesthetics as elements in their valuation. Beretta provides a well-researched study of mineralogical traditions from the early modern collectors who classified minerals wholly on external characters, as was common with botanical and zoological collections, to those in the latter half of the eighteenth century who used chemical characters. Much of the chapter is devoted to Antoine Lavoisier, whose work was outside the old natural-history tradition and contributed to his complex theories on the history of the Earth.

Janet Browne explores how collections may provide an entrée into a higher social group the scientific community - and includes a particularly interesting account of how Darwin used his collections to break into academic circles and attain credibility.

Ana Carneiro looks in considerable detail at the lively discussion between the Swedish anatomist and palaeobotanist Alfred Nathorst, the aristocratic Gaston de Saporta and the Portuguese geologist Nery Delgado on what are now thought to be fossil trilobite tracks. Carneiro's thesis is that the interpretations of these objects by these three protagonists were influenced by their social and scientific backgrounds; this is interesting, but might well have been argued in rather less than 42 pages.

From a natural historian's viewpoint, these

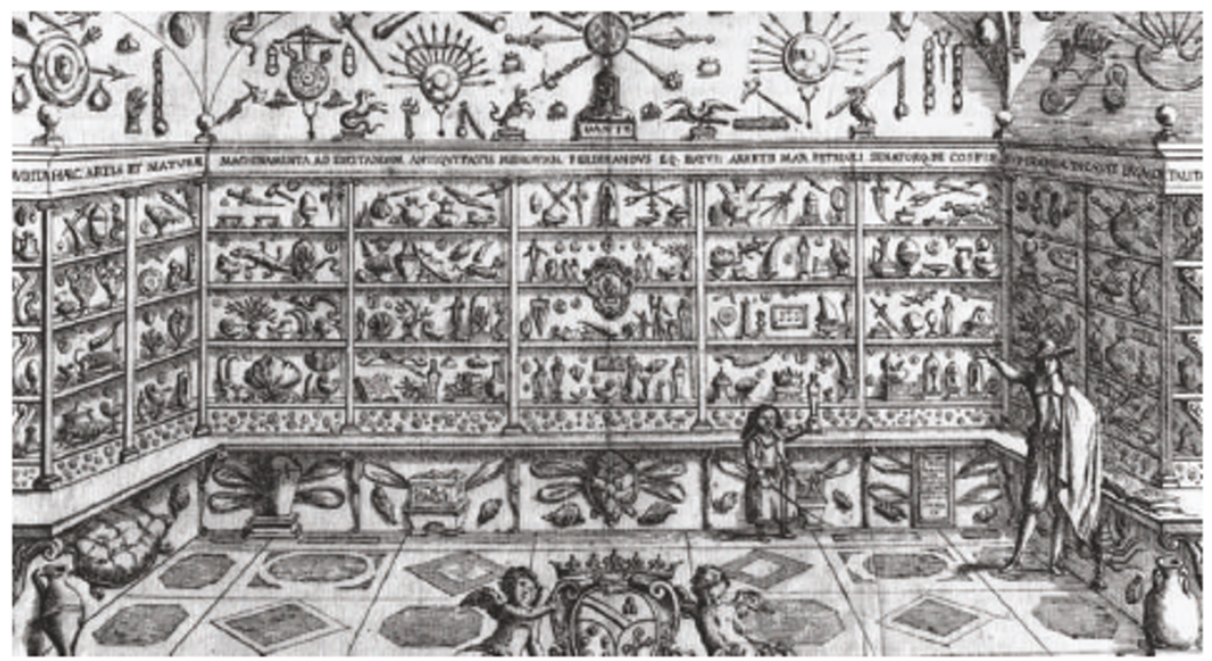

Shelf life: by the late seventeenth century, Italy was home to some remarkable collections.

papers are far removed from the more familiar accounts of how collections, collectors and specimens contributed to our knowledge of the natural world, as they also address the largely unexplored subject of the how the collections affected their collectors, an avenue of research that would reward further work. This scholarly work comprises a collection of papers that were given at a conference entitled 'From Private to Public' held in Ravenna, Italy, in June 2004. It is made accessible by the palpable enthusiasm of the authors for their subject, and is well produced with many relevant illustrations. Kathie Way iscollection managerin the Division of Higher Inver tebrates, the Natural History Museum, Cromwell Road, London SW7 5BD, UK, and honorary curator of the zoological collections of the Linnean Society of London.

MORE ON THE HISTORY OF MUSEUMS

Cabinets For the Curious: Looking Back at

Early English Museums

by Ken Arnold

Ashgate: 2006. 297 pp. $€ 47.50$

\section{THEATRE}

\section{A defining moment for bioethics}

\section{Biblioethics: A User's Dictionary \\ Directed by Luca Ronconi \\ Teatro Vittorio in Turin, Italy}

\section{Alison Abbott}

Luca Ronconi, one of Italy's most revered and provocative theatre directors, is at his most inspired when faced with the seemingly impossible. And the challenge of bringing a dictionary of bioethical terms to the stage is about as close to impossible as you can get. Yet Ronconi pulls it off in Biblioethics: A User's Dictionary, one of a series of five plays commissioned to promote Turin as a city of avantgarde culture on the occasion of the 2006 Winter Olympics.

Ronconi included science as one of the grand themes of contemporary humanity addressed in his series Domani, or Tomorrow. His other themes were war, history, politics and finance.

Biblioethics is not an easy play: there is no plot, just scenes that reflect on the meaning of bioethics. Ronconi disdains any technique of emotional persuasion. But he holds the attention of the audience by forcing them to participate. The theatre has been turned into a disorientating maze of small rooms separated

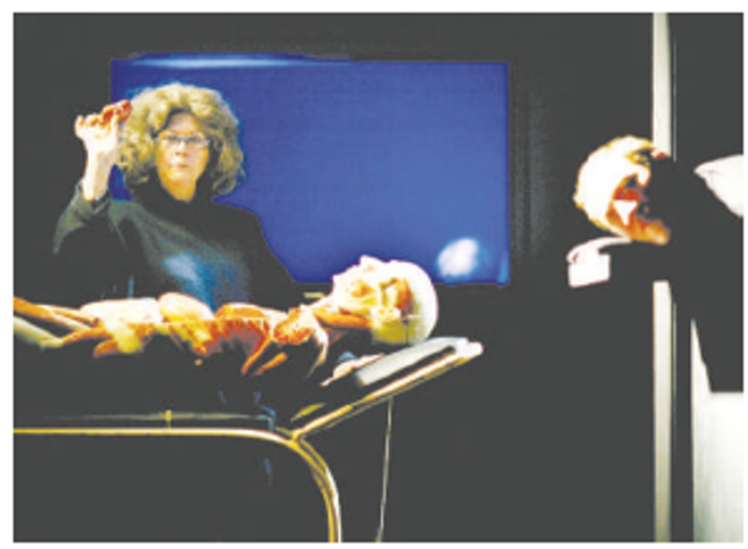

Biblioethics is helping the public come to terms with bioethics.

by thin partitions between which the audience has to move.

In the first room, the entire audience watches a video screen on which is projected the head of an actor reading out dictionary definitions of bioethical terms, beginning with the two that Ronconi considers central to bioethics: personal choice and informed consent. In the second room, actors playing representative characters - a dinician, a religious bioethicist, a secular bioethicist, and male and female students - present their points of view. They speak emotionally, but their manners are deliberately detached.

The audience then divides itself between the subsequent rooms, which are dedicated to 12 different terms, including organ donation, the Nuremberg code, euthanasia and cloning. The playlets in each room run concurrently, and viewers must focus on their chosen theme, trying not to be distracted by the voices drifting across from other rooms. They realize later that they have had the chance to see only half of the performances. Their personal choices excluded them from other options, from the sharing of other points of view.

Played out in Ronconi's hallmark monochromatic settings, the intellectual charge is animating, but the emotional charge is absent.

Biblioethics: $A$ User's Dictionary can be seen at the Teatro Vittorio in Turin until 12 March. Alison Abbott is Nature's senior European correspondent. 